\title{
Editorial
}

\section{Innovation in education technology: What is the point? \\ Is immersive education the next step?}

\author{
Andrea Garavaglia ${ }^{\mathrm{a}}$, editor \\ ${ }^{a}$ University of Milan - Bicocca, Italy, andrea.garavaglia@unimib.it, https://orcid.org/0000-0003-1408-2492
}

Keywords: innovation, immersive education, learning analytics, augmented learning, augmented reality, virtual reality

\section{Introduction}

What is innovation? What is innovative? These terms reveal interesting implications when coupled with the teaching and learning process. The introduction of new technologies in teaching has often been considered innovative, but over time, first experiences have revealed that it is necessary to consider the entire educational system and outcomes to understand the terms of real change.

\section{What is innovative?}

Richard Lyons, an economist, describes innovation as 'fresh thinking that creates value'. The creation of a value is particularly important in education because we can assume that the value created is the difference between the previous state and the final state that has resulted as the effect of an educational process.

Rick Miller, President of Olin College of Engineering, offers this definition: 'Innovation may then be defined as the process of having original ideas and insights that have value, and then implementing them so that they are accepted and used by significant numbers of people. By this definition, a major innovation is one that is so successful that soon after its introduction few people an even remember what life was like before the innovation was introduced' (2011, p. 2). The definition provided by Miller is very interesting because it emphasizes the fact that the lack of dissemination of a good solution actually implies a type of futility relative to another less-good solution that has been widely applied in the teaching community.

Peter Drucker (2002) states, 'Innovation is the specific function of entrepreneurship, whether in an existing business, a public service institution, or a new venture started by a lone individual in the family kitchen. It is the means by which the entrepreneur either creates new wealth-producing resources or endows existing resources with enhanced potential for creating wealth'.

Razeghi focuses on the needs of a group as a starting point to work on an innovation that helps to meet the said needs. In a book on generation of ideas, he stated, 'innovation is not the result of thinking differently. It is the result of thinking deliberately (in specific ways) about existing problems and unmet needs'. (2008, p. 24).

The aspect of well-being is highlighted by Barack Obama; in fact, his definition of innovation is 'the creation of something that improves the way we live our lives'.2 Applied to education, this means that novelty is recognised in terms of an improvement in the conditions for participation by each member of a group or community, regardless of whether they perform the role of a teacher or a learner.

\footnotetext{
${ }^{1}$ Something new under the sun: A special report on innovation. (2007, October 13). The Economist. Retrieved from http://www.economist.com/node/9928154.

${ }^{2}$ Business Week's "In" subsection, p. 6, November 2007
} 
Innovation is the result of a process of creation and several research reports have emphasised it clearly. One of the most interesting works is a study conducted on training models for innovators, conducted by Tony Wagner (2012): he focuses on the importance of creativity in innovation, so that he identifies the essential elements of innovation as 'motivation', 'expertise' and mostly 'critical thinking'. In another research conducted by General Electric in 2011, a thousand of senior business executives were interviewed about innovation. One of the most interesting results was that $69 \%$ of them agreed that currently, innovation is driven more by people's creativity than by high-level scientific research.

\section{What is not innovative?}

Starting from these definitions, it is interesting to explore the different ways of conceiving innovation in teaching and learning using new technologies. The basic elements involved are two: the technologies introduced and the methodologies proposed. The combination of these two elements can determine the definition of the following three states:

- A new technology that does not involve a change in methodology: generally, this innovation does not affect learning because the experience is the same, and the technology can help increase the motivation of the learners using it in the initial period to explore the new instrumentation;

- A methodological innovation built using proven technologies over time: this solution can affect learning;

- An innovation that affects both methodologies and the technology. In this case, if the changes introduced meet at least part of the training needs, one can get interesting results in terms of both learning and motivation.

This categorisation could seem like a simplification considering the complicated realities of the different educational systems, but it may be useful to identify and distinguish three sets of problems:

The first problem is to avoid doing the same things with a new instrument. It is not uncommon to observe training proposals characterised by fixation on an old pattern that is repeated using different technologies. In this case, it is believed that the introduction of new technological solutions can result in improvement of learning.

The second issue is how to do new things with a new tool: when it becomes evident that the simple introduction of a technology is not enough, one faces the need to find an innovation in teaching method. It is a complex operation as effectiveness is strongly connected to the training needs of the group of learners.

The third problem concerns universality: hardly any innovation in education is universal; often, the methodological proposals are not accepted by all recipients alike.

Using another perspective, it is also a question of probability: how to maximise the probability of improving learning? One possible option lies in the future application of the results of research related to learning analytics (Elias, 2011; Fritz, 2010) or evidence-based education (Hattie, 2009) as an innovation that can introduce new operating standards in teaching design.

\section{The next trend in learning with technologies: augmented reality, virtual reality and Internet of Things}

In studying the innovation criteria of a training process, I tried to imagine which of the new technologies that are spreading in recent times produce the conditions necessary to get an innovation in methodology, especially in terms of strengthening the learning conditions. I suggest herein a proposal built on the basis of three major innovations that are entering the mass market as augmented reality (AR), virtual reality and Internet of Things (IoT).

These three innovations are strongly related to the possibility of enriching the learning experience involving the learner, so as to obtain an immersive learning situation.

\subsection{Learning with AR and mixed reality}

AR 'refers to all cases in which the display of an otherwise real environment is augmented by means of virtual (computer graphic) objects' (Milgram \& Kishino, 1994, p. 2). The term Mixed Reality was proposed to highlight the use of devices that involve the merging of real and virtual worlds, but it is used less often than AR because the evolution of technology is substantially making the distinction less significant. Probably, Considering that Microsoft promotes this distinction by proposing HoloLens as a mixed reality system, it could spread the mixed reality concept using systems that cover the entire field of vision (such as helmets and visors) and AR with part-coverage field of vision (such as tablets or smartphones).

$\mathrm{AR} /$ mixed reality can provide a learning experience enriched with content and connections to other experiences linked to elements that are observed by the learner in the surrounding environment. It is an educational solution that could spread widely because the devices necessary to be able to materialize these applications, such as modern smartphones or tablets, are already available on the market at affordable prices. 


\subsection{Immersive and situated learning with virtual reality}

Virtual reality is a way to create a duplicate of an environment with a specific technology that can be explored and interacted with by a person (Ausburn \& Ausburn, 2004). It is possible to create an imaginary world or reproduce a real context.

One of the most interesting environments is AltspaceVR (http://altvr.com/), an application to create immersive experience, natively compatible with the leading virtual reality devices that are distributed from this year (2016) on the market. It can completely substitute a videoconference system. This application has the ability to create low-cost scenarios, allowing those involved in education to implement early solutions, managing to maintain this return on investment.

Both AR and virtual reality allow the use of input methods with advanced commands based on the detection of movement of the body (such as Kinect and Leap Motion) or MOCAP (Motion CAPture) systems, more evolved as Perception Neuron. The use of input systems that allow the learner to interact with the world in a natural way, without a keyboard, mouse or gamepad, can increase the levels of immersion and establish situated learning episodes (Rivoltella, 2013) or authentic scenarios wherein the subjects are able to operate very similarly to the real situation.

\subsection{Adaptive learning with IoT}

IoT is a system of interrelated 'things' such as devices, objects, people, machines or animals. Each of them can communicate with the others in the same place or through the Internet. Every 'thing' has an Internet Protocol address, so schools and institutes can keep track of information and manage and analyse big data on students both online and in their presence. The next challenge would be to understand how and what data to analyse in order to obtain reports and dashboards that provide frameworks and indications of the progress of educational processes.

Another way to use IoT is to exploit the information provided by the different objects to build adaptive learning processes. All projects based on methods such as mastery learning, individualisation or customisation can get additional benefit from the exploitation of the data recorded by the various interconnected objects. The new challenge here will be to be able to easily implement the programming of different combinations of teaching steps.

IoT could be also useful for students with special needs, e.g., through devices that change the mode of input or output in the vicinity of students with particular disabilities.

Naturally, these are only hypotheses and business ideas that both the world of education and the research world can develop in order to build learning situations that present new opportunities previously unfeasible.

\section{References}

Ausburn, L.J., Ausburn F.B. (2004). Desktop virtual reality: a powerful new technology for teaching and research in industrial teacher education. Journal of Industrial Teacher Education, 41 (4), pp. 33-58.

Cachia R., Ferrari, A., Ala-Mutka K. M., Punie, Y. (2010). Creative Learning and Innovative Teaching: Final Report on the Study on Creativity and Innovation in Education in the EU Member States. Publications Office of the European Union. http://dx.doi.org/10.2791/52913

Drucker, P. (2002, August), The discipline of innovation. Harvard Business Review. Retrieved from https://hbr.org/2002/08/the-discipline-of-innovation

Elias, T. (2011). Learning analytics: Definitions, processes and potential. Unpublished Internal Whitepaper of Athabasca University, Canada.

Fritz, J. (2010). Classroom walls that talk: Using online course activity data of successful students to raise selfawareness of underperforming peers. The Internet and Higher Education, 14(2), 89-97.

General Electric (2011). GE Global Innovation Barometer 2011. Retrieved from http://files.gereports.com/wpcontent/uploads/2011/01/GIB-results.pdf

Hattie, J. A. C. (2009). Visibile Learning. A synthesis of over 800 meta-analyses relating to achievement. London: Routledge.

Milgram, P., \& Kishino, F. (1994). A taxonomy of mixed reality visual displays. IEICE Transactions on Information Systems, (12). Retrieved from http://vered.rose.utoronto.ca/people/paul_dir/IEICE94/ieice.html

Miller, R. K. (2011, May). How do you recognize and cultivate potential innovator?. Paper presented at Olin College. Retrieved from http://goo.gl/7Q0MW9

Razeghi, A. (2008). The riddle: where iedas come from and how to have better ones. San Francisco: Jossey-bass.

Rivoltella P. C. (2013). Fare didattica con gli EAS. Brescia: La Scuola.

Something new under the sun: A special report on innovation. (2007, October 13). The Economist. Retrieved from http://www.economist.com/node/9928154

Wagner, T. (2012). Creating Innovators. The making of young people who will change the world. New York: Scribner. 